Torsional forces are the ultimate cause of fracture (Böstman 1986). We could obtain no exact data on the frequency of left-handedness in the corresponding general population, but the proportion of left-handers among the patients with non-rotational fractures observed in this study $(8 \%)$, is close to the presumed universal prevalence of left-handedness, namely one in ten of the population (Turner 1993).

Our results confirm the hypothesis that left-handedness is associated with an increased rate of at least some types of accident. It is, however, of special interest that our results indicate that this susceptibility to injury may not be general and non-specific, but instead rather specific. In our study the increased risk seemed to be associated with rotationrelated deviations from the normal mechanisms of posture control and motor performance that are required in attempts to parry a fall. Future research may be able to identify other types of injury which show a significant over-representation of left-handed patients.

No benefits in any form have been received or will be received from a commercial party related directly or indirectly to the subject of this article.

\section{REFERENCES}

Aggleton JP, Kentridge RW, Neave NJ. Evidence for longevity differences between left handed and right handed men: an archival study of cricketers. J Epidemiol Community Health 1993;47:206-9.

Böstman OM. Spiral fractures of the shaft of the tibia: initial displacement and stability of reduction. $J$ Bone Joint Surg $[\mathrm{Br}]$ 1986;68-B:462-6.

Coren S. Left-handedness and accident-related injury risk. Am J Public Health 1989;79:1040-1.

Minns RJ, Bremble GR, Campbell J. The geometrical properties of the human tibiae. J Biomech 1975;8:253-5.

Turner BS. Left handedness (Editorial). BMJ 1993:307:1577-8

\title{
MODIFIED REAMERS FOR FUSION OF THE FIRST METATARSOPHALANGEAL JOINT
}

\section{J. A. JEFFERY, L. F. FREEDMAN}

Fusion of the first metatarsal joint for hallux valgus or hallux rigidus was first described by Clutton in 1892. Since then, many different techniques have been described for preparing the bony surfaces and maintaining position until union. We report the use of specially designed powered reamers which simplify the operation, maximise the bony contact and facilitate correct alignment.

Operative technique. Through a standard dorsomedial incision the capsule and periosteum are reflected. Prominent osteophytes are trimmed, and the hallux is flexed and abducted to expose the whole joint surface. The new reamers (Fig. 1) are then used to remove articular cartilage and expose subchondral bone. These closely match the curves of the metatarsal head and phalangeal base and produce concentric surfaces which can easily be aligned in the correct position with wide bony apposition. The posi-

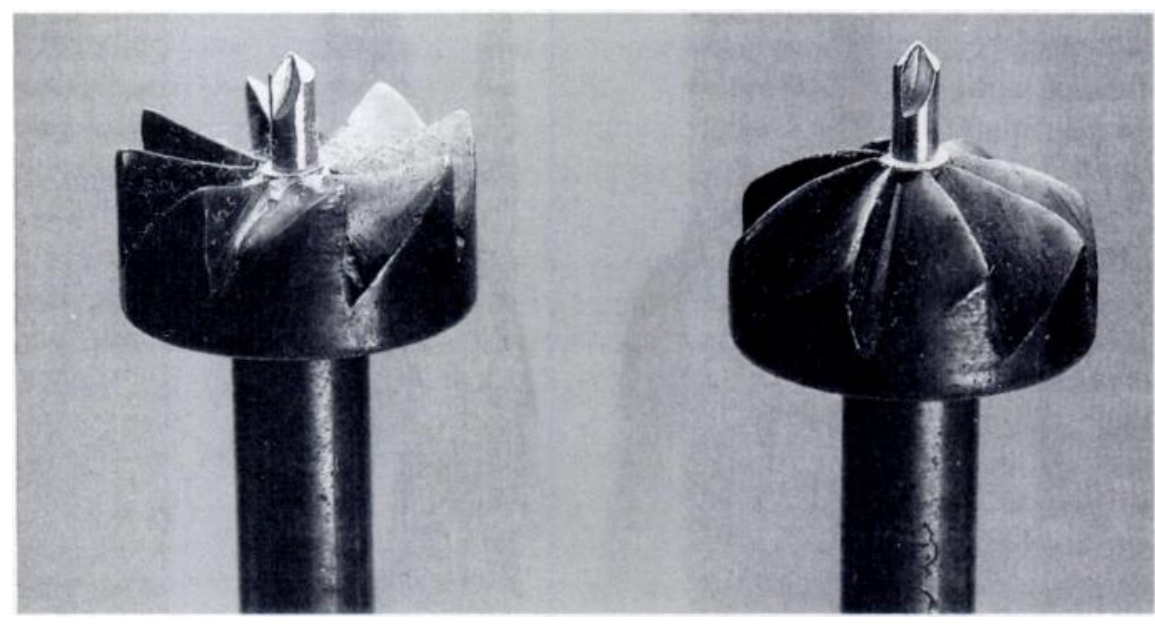

Fig. 1

J. A. Jeffery. FRCS. Senior House Officer

L. F. Freedman, FRCS. Consultant Orthopaedic Surgeon

Department of Orthopaedics, Northwick Park Hospital NHS Trust, Watford Road, Harrow, Middlesex HAI 3UJ. UK.

Correspondence to Mr J. A. Jeffery at 31 Park Road. High Barnet, Hertfordshire, EN5 5SE, UK.

(1)1995 British Editorial Society of Bone and Joint Surgery

$0301-620 X / 95 / 2 R 35 \$ 2.00$

J Bone Joint Surg $|B r|$ 1995:77-B:328-9.

Received 20 April 1994: Accepted 8 July 1994

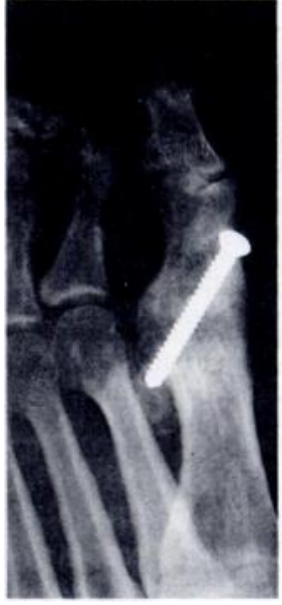

Fig. 2a

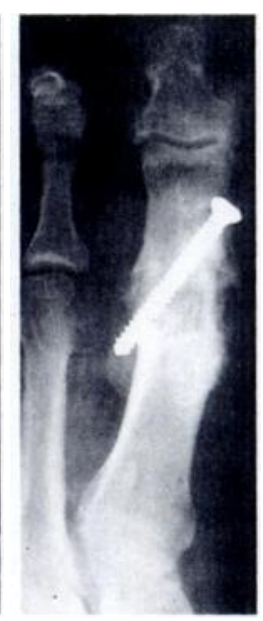

Fig. 2b tion is held with a $3.5 \mathrm{~mm} \mathrm{AO}$ lagged screw obliquely through the base of the proximal phalanx (Fig. 2). Postoperatively, the foot is protected in plaster for six weeks, which is changed after two weeks for suture removal. Removal of the lag screw is required only if its head produces pressure symptoms.

Results. Twenty such operations have been performed by the senior author (LF) on 17 patients ( 3 male) with a mean 
age of 50 years. In ten patients surgery was for hallux valgus; six fusions were performed in five non-rheumatoid patients and five in five rheumatoid patients. In five patients (one bilateral procedure) surgery was for painful hallux rigidus. In the other two patients (three feet) the arthrodesis was used to salvage a poor result from previously performed Keller's arthroplasties. At 12 weeks postoperatively, 19 of the 20 joints had united clinically and radiographically. The one with nonunion at 12 weeks was in a 25 -year-old woman with hallux rigidus who subsequently required a second fusion, but then achieved bony union.

Discussion. McKeever (1952) described a peg and socket fusion, using an osteotome to shape the metatarsal head and a Kerrison rongeur to make a socket in the proximal phalanx. This gave good results in experienced hands, but positioning while obtaining maximum bony contact was difficult and there was always some shortening. Marin (1960) devised matching hand-held reamers and Wilson (1967) modified these to provide a pencil-sharpening type of cutter for the metatarsal head. Wilkinson (1978) reported $100 \%$ fusion in 83 patients with these. This method, however, causes shortening and allows no adjustment of position. This is critical since interphalangeal osteoarthritis and malrotation are major causes of the failure of surgery (Fitzgerald 1969).

The modified reamers which we describe provide rapid cutting and allow accurate adjustment of the position of the surfaces. A minimal amount of bone is removed, thereby maintaining length while achieving maximum body contact. This is particularly important when revising a failed arthrodesis or Keller's arthroplasty.

No benefits in any form have been received or will be received from a commercial party related directly or indirectly to the subject of this article.

\section{REFERENCES}

Clutton HН. The treatment of hallux valgus. St Thomas's Hospital Reports 1984;NH22:1-12.

Fitzgerald JAW. A review of long-term results of arthrodesis of the first metatarso-phalangeal joint. J Bone Joint Surg [Br] 1969;51-B:48893.

Marin GA. Arthrodesis of the first metatarsal joint for hallux valgus and hallux rigidus. Guy's Hospital Reports 1960;109:174-8.

McKeever DC. Arthrodesis of the first metatarso-phalangeal joint for hallux valgus, hallux rigidus and metatarsus primus varus. $J$ Bone Joint Surg [Am] 1952;34-A:129-34.

Wilkinson J. Cone arthrodesis of the first metatarsal joint. Acta Orthop Scand 1978;49:627-30.

Wilson JN. Cone arthrodesis of the first metatarsophalangeal joint. J Bone Joint Surg [Br] 1967;49-B:98-101.

\title{
CEMENT HYPERSENSITIVITY: A CAUSE OF ASEPTIC LOOSENING?
}

\author{
F. S. HADDAD, N. J. LEVELL, P. M. DOWD, A. G. COBB, G. BENTLEY
}

A proportion of cemented total hip replacements still fail due to aseptic loosening. Several hypotheses have been proposed to explain this such as mechanical factors (Charnley 1979; Jasty et al 1991) and biological reactions to the implanted foreign material, particularly polyethylene debris (Sutherland et al 1982; Jasty et al 1986). Most patients with cemented hip replacements achieve satisfactory long-term fixation but there is a small subgroup who suffer early loosening and in whom polyethylene debris is highly unlikely to be responsible (Jones and Hungerford 1987).

Loosening usually occurs at the cement-bone interface where a synovium-like membrane forms which has the

F. S. Haddad, BSc, MB BS, Senior House Officer

A. G. Cobb, BSc, FRCS. Senior Lecturer

G. Bentley, MCh. FRCS, Professor of Orthopaedics

The Institute of Orthopaedics. The Royal National Orthopaedic Hospital

NHS Trust, Brockley Hill, Stanmore, Middlesex HA7 4LP, UK

N. J. Levell, MRCP. Senior Registrar in Dermatology

P. M. Dowd, MD, FRCP. Senior Lecturer in Dermatology

University College School of Medicine. Gower Street. London WIN 8AA,

UK.

Correspondence to Mr F. S. Haddad at 46B Hanover Gate Mansions, Park Road, London NWI 4SN, UK.

(1)1995 British Editorial Society of Bone and Joint Surgery

$0301-620 X / 95 / 2 R 32 \$ 2.00$

J Bone Joint Surg [Br] 1995:77-B:329-30.

Received 25 October 1993: Accepted 26 Mav 1994 capacity to produce prostaglandin $\mathrm{E}_{2}$, collagenase and other osteolytic products such as interleukin-1 factor and tumour necrosis factor (Eskola et al 1990). The macrophage/giantcell reaction that occurs has been likened to type-IV hypersensitivity, and although it is not clear whether this is a primary or a secondary phenomenon, intensive studies have been made to find allergens within the implanted materials. High concentrations of cobalt, chromium and nickel have been implicated particularly in metal-to-metal prostheses (Evans et al 1974; Benson, Goodwin and Brostoff 1975) and the possibility of titanium sensitivity has been suggested (Lalor et al 1991). There has, however, been more interest in the bone cement itself. Many cases of allergic contact dermatitis have been reported in dental and orthopaedic surgeons (Pegum and Medhurst 1971; Fries, Fisher and Salvati 1975) and allergic contact dermatitis due to methacrylate resins has been shown to occur in relation to hearing aids, spectacle frames and limb-replacement prostheses (Romaguera et al 1989; Marren, De Berker and Powell 1991). Methacrylate is known to be an allergen in a small percentage of the population (Cavelier et al 1981).

We report a patient who had loosening of rapid onset after total hip replacement and who was subsequently found to be hypersensitive to one of the components of bone cement.

Case report. A 60-year-old joiner with no personal or 